\title{
Establishment of a Representative Practice-based Research Network (PBRN) for the Monitoring of Primary Care in Switzerland
}

\author{
Kevin Selby, MD, Jacques Cornuz, MD, MPH, and Nicolas Senn, MD, PhD
}

Data are urgently needed to better understand processes of care in Swiss primary care (PC). A total of 2027 PC physicians, stratified by canton, were invited to participate in the Swiss Primary care Active Monitoring network, of whom 200 accepted to join. There were no significant differences between participants and a random sample drawn from the same physician databases based on sex, year of obtaining medical school diploma, or location. The Swiss Primary care Active Monitoring network represents the first large-scale, nationally representative practice-based research network in Switzerland and will provide a unique opportunity to better understand the functioning of Swiss PC. (J Am Board Fam Med 2015;28:673-675.)

Keywords: Practice-based Research, Primary Health Care, Switzerland

There is a striking lack of data on primary care (PC) in Switzerland, especially regarding processes of care. ${ }^{1,2}$ We used the opportunity presented by the realization of a nationwide PC physicians' survey in 2012 to launch a research program focused on better understanding Swiss PC: the Swiss Primary Care Active Monitoring (SPAM) program. The participating physicians will form a practicebased research network (PBRN) dedicated to Swiss $\mathrm{PC}$ health system research.

\section{Methods}

The Quality and Costs of Primary Care in Europe (QUALICOPC) survey served as a starting-point

This article was externally peer reviewed.

Submitted 29 March 2015; revised 11 June 2015; accepted 16 June 2015.

From the Department of Ambulatory Care and Community Medicine, University of Lausanne, Lausanne, Switzerland.

Funding: Funding for the Quality and Costs of Primary Care in Europe (QUALICOPC) study in Switzerland came from the Swiss Federal Office of Statistics. The University of Lausanne received technical and financial support for QUALICOPC from the Netherlands Institute for Health Services Research (NIVEL) in Utrecht, the Netherlands. NS receives salary funding from the Leenaards Foundation. Conflict of interest: none declared.

Corresponding author: Kevin Selby, MD, Department of Ambulatory Care and Community Medicine, University of Lausanne, Rue de Bugnon 44, 1011 Lausanne, Switzerland (E-mail: kevin.selby@hospvd.ch). for creating the SPAM network. ${ }^{3}$ A comprehensive list of PC physicians (PCPs) was formed using lists of member from the Association of Family Doctors and Pediatricians and the Swiss Society of General Internal Medicine (Figure 1). A random preselection of 2027 PCPs, stratified by canton according to population, were asked whether they would be willing to participate in a research network that was subsequently labeled the SPAM network. For means of comparison, a random sample was drawn from the same sample of 2027 preselected PCPs (the "comparison group"; Table 1). The postal code of responders was used to classify them into 3 categories per the classification of the Federal Office of Statistics: urban center, suburb, and rural commune.

Frequencies, means \pm standard deviations, or medians were used as appropriate. Comparisons were made using the $\chi^{2}$ and Student $t$ tests, with significance set at 0.05 .

\section{Results}

Of 2027 PCPs contacted, 200 (10\%) agreed to participate in the SPAM network and 199 completed the QUALICOPC questionnaire (Figure 1). The SPAM network and comparison group contain similar numbers of women $(23 \%$ vs $21 \%$; $P=.629)$ and the participants have a similar 
Figure 1. Selection of primary care physicians (PCPs) for the Swiss Primary Care Active Monitoring (SPAM) network. QUALICOPC, Quality and Costs of Primary Care in Europe study.

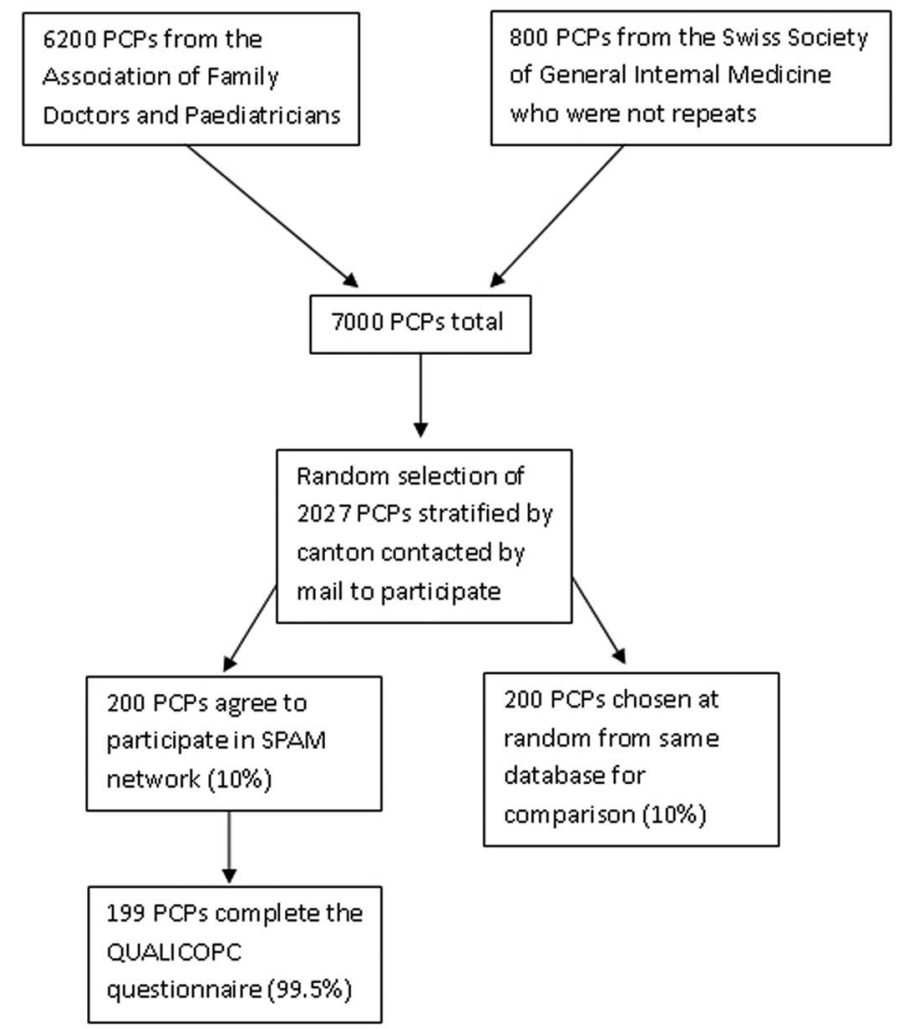

mean age $(53.8 \pm 0.59$ vs $53.4 \pm 0.56$ years; $P=$ $.575)$. The SPAM network contains significantly more PCPs from French- and Italian-speaking re-

gions (39\% vs $24 \%$ non-German; $P=.004)$. The breakdown of PCP practice location shows nearly equal portions of $\mathrm{PCPs}$ practice in an urban center

Table 1. Comparison of Primary Care Physicians Participating in the Swiss Primary Care Active Monitoring Network $(\mathrm{n}=200)$ Compared with a Random Sample of Primary Care Physicians Chosen as a Comparison Group $(\mathrm{n}=200)$

\begin{tabular}{|c|c|c|c|}
\hline Characteristic & $\begin{array}{l}\text { PCPs from SPAM } \\
\quad(\mathrm{n}=200)\end{array}$ & $\begin{array}{l}\text { PCPs from Comparison } \\
\quad \text { Group }(\mathrm{n}=200)\end{array}$ & $P$ Value \\
\hline Female sex $(\%)$ & $46(23)$ & $42(21)$ & .629 \\
\hline Member of FMH (\%) & $183(92)$ & $186(93)$ & .575 \\
\hline Mean year of diploma (SD) & $1983(7.60)$ & $1984(7.94)$ & 629 \\
\hline Mean age, years $(\mathrm{SD})^{*}$ & $53.8(7.60)$ & $53.4(7.94)$ & .629 \\
\hline Primary language (\%) & & & .004 \\
\hline German & $123(62)$ & $152(76)$ & \\
\hline French & $69(35)$ & $46(23)$ & \\
\hline Italian & $8(4)$ & $2(1)$ & \\
\hline $\begin{array}{l}\text { Practice Location Based on Federal Office of Statistics } \\
\text { Categorization, } \mathrm{n}(\%)\end{array}$ & & & .177 \\
\hline Urban center & $65(33)$ & $70(35)$ & \\
\hline Suburbs & $78(39)$ & $76(38)$ & \\
\hline Rural & $57(29)$ & $54(27)$ & \\
\hline
\end{tabular}

*Age estimated by adding 25 years to the year when participants received their medical school diploma.

FMH, Swiss Medical Association; PCP, primary care physician; SD, standard deviation; SPAM, Swiss Primary Care Active Monitoring network. 
(33\% vs $35 \%$ ), suburbs ( $39 \%$ vs $38 \%$ ), or a rural area $(29 \%$ vs $27 \%)(P=.177)$.

\section{Discussion}

To our knowledge, 2 other PBRNs collect PC data in Switzerland. First, the Swiss Sentinel Surveillance Network consists of a voluntary network of PCPs who provide firsthand data for the epidemiologic surveillance of diseases, mainly seasonal influenza. ${ }^{4}$ Second, the FIRE network, based in Zürich, pools data from the electronic health records of approximately 60 physicians. ${ }^{5}$ These existing PBRNs focus on the epidemiology of infectious and chronic diseases in PC. The SPAM network, with its focus on processes of care in PC and national representation, should be complementary to other efforts.

The representativeness of the SPAM network may be limited by the low response rate of $10 \%$ and that the comparison did not include elements of daily clinical practice. When respondents are compared with a random selection of 200 PCPs from the same databank, however, they are similar in distribution of sex, age, and practice location.

Future challenges for the SPAM network will likely be similar to those of all PBRNs: retaining PCPs, obtaining continuous funding to maintain infrastructure, and ensuring that the research topics chosen are relevant to the participating PCPs and their patients. ${ }^{6}$ Current measures include a semiannual newsletter, workshops at congresses, and including practicing PCPs in the steering committee. A regular renewal of the network will be critical in maintaining a robust, representative cohort.

\section{Conclusion}

This report presents the SPAM network and compares its PCPs with a randomly chosen comparison group, demonstrating that this new network is likely representative of PCPs in Switzerland. The SPAM network represents the first large-scale PBRN in Switzerland dedicated to health systems research.

The authors thank the Netherlands Institute for Health Services Research (NIVEL) for their help.

\section{References}

1. Kringos DS, Boerma, WG, Hutchinson A, Saltman RB. Building primary care in a changing Europe. Copenhagen, Denmark: World Health Organization; 2015.

2. Organisation for Economic Co-operation and Development, World Health Organization. OECD reviews of health systems: Switzerland. Paris: Organisation for Economic Co-operation and Development; 2011.

3. Schäfer WL, Boerma WG, Kringos DS, et al. QUALICOPC, a multi-country study evaluating quality, costs and equity in primary care. BMC Fam Pract 2011;12:115.

4. Stuck AK, Tauber MG, Schabel M, Lehmann T, Suter H, Muhlemann K. Determinants of quinolone versus trimethoprim-sulfamethoxazole use for outpatient urinary tract infection. Antimicrob Agents Chemother 2012;56:1359-63.

5. Busato A, Bhend H, Chmiel C, et al. Improving the quality of morbidity indicators in electronic health records in Swiss primary care. Swiss Med Wkly 2012; 142:w13611.

6. Tierney WM, Oppenheimer CC, Hudson BL, et al. A national survey of primary care practice-based research networks. Ann Fam Med 2007;5:242-50. 